\title{
Clinical Manifestations of Cardiac Disease in Patients with End Stage Renal Disease Under Maintenance Hemodialysis in a Tertiary Level Hospital of Nepal
}

\author{
Kumar Roka ${ }^{1}$ Pratibha Bista Roka ${ }^{2}$
}

${ }^{1}$ Department of Medicine, Shree Birendra Hospital, Kathmandu ${ }^{2}$ Department of Pathology, Bir Hospital, Kathmandu, Nepal.

\section{ABSTRACT}

Introduction: End stage renal disease presents with multiple clinical and systemic manifestations. The aim of the present study was to identify the early cardiac and other morbidities in end stage renal disease (ESRD) patients who were under maintenance hemodialysis. Methods: This was an observational, prospective study conducted in fifty established ESRD patients of 20 to 74 years under maintenance hemodialysis in Nephrology unit of Shree Birendra Hospital. Clinical examination, laboratory parameters, electrocardiogram and echocardiography findings were used to identify the morbidities. Results: Among all patients enrolled in the study $88.7 \%$ had anemia, $64.2 \%$ systolic murmurs, $62.26 \%$ pedal edema, $73.6 \%$ fatiguability, $71.7 \%$ angina, $24.4 \%$ palpitations and $13.2 \%$ had breathlessness on exertion. $62.26 \%$ of the patients had hypertension and $13.20 \%$ had diabetes. In the electrocardiogram, prolonged QTc was observed in $10.4 \%$, followed by $\mathrm{T}$ wave inversion in $9.4 \%$ and finally low voltage complex comprised $7.6 \%$. The echocardiogram showed left ventricular diastolic dysfunction in $58.5 \%$, left ventricular hypertrophy (overall type) $49 \%$ and valvular lesion like mitral regurgitation and tricuspid regurgitation $83 \%$ and $58.5 \%$ respectively. Conclusion: Cardiac co-morbidities are common in patients diagnosed with ESRD on maintenance hemodialysis.

Keywords: end stage renal diseases; dialysis; echocardiography

\section{INTRODUCTION}

Among the various systemic manifestations, the cardiac involvement is the major cause of death in patients undergoing maintenance hemodialysis, accounting for $40 \%$ of deaths in international registries. ${ }^{1}$ When compared to a non-renal cohort age range of 45 to 64 years, the death rate in dialysis cohort of similar age is 3.5 times higher. $^{2}$ The prevalence of clinical manifestations of cardiac disease at the initiation of end stage renal disease (ESRD) therapy is high and those manifestations independently predict death in these patients 3,4 . MJSBH Vol 15 Issue 1 Jan- Jun 2016
Greaves et al. has reported carious cardiac diseases in patients with end stage renal disease $^{5}$. In the cohort studies done by Linder et al. comprising ninety patients with initial stage of end stage renal disease, it was seen that left ventricular hypertrophy adversely and independently influenced the outcome of the patients $^{6,7}$.

Correspondence: Kumar Roka, Department of Medicine, Shree Birendra Hospital, chaunni, Kathmandu, Nepal. Email: roka_dr@hotmail.com 
Though already seen in many studies performed mainly in western population, literature on correlation between ESRD and cardiac morbidities in Nepalese population is scarce. Thus the objective of this study was to observe, evaluate and correlate the clinical, electrocardiogram and the echocardiography findings in patients undergoing maintenance hemodialysis for ESRD.

\section{METHODS}

The study was conducted at Department of Nephrology of Shree Birendra Hospital, Kathmandu from July 2012 to July 2014. Patients who had persistent azotemia in preceding three months and who had minimum six sessions of hemodialysis were included in this study. Patients with evidence of reversible causes of renal insufficiency such as acute renal failure, acute interstitial nephritis, acute glomerulonephritis and patients with preexisting heart disease were excluded from the study. Similarly patients less than 20 years and more than 70 years of age were excluded.

Anemia was assessed by pallor $\&$ hemoglobin level. Jugular venous pressure, pedal edema and murmurs were assessed by standard clinical methods. Blood pressure was recorded on both the standing and lying position. The twelve lead chest ECG was done and twodimensional echocardiography was used to assess the cardiac function status.

\section{RESULTS}

Male and female constituted $56.6 \%$ and 43.4 $\%$ respectively. Most subjects were of 51-60 years age group followed by 41-50 years (table 1). The clinical findings that were most common were pallor, systolic murmur, pedal edema and hypertension (table 2). The commonest electrocardiogram findings were
Table 1: Age and sex distribution of participants of the study.

\begin{tabular}{|l|c|c|c|}
\hline \multicolumn{1}{|l|}{ Age (in years) } & Male & Female & $\%$ \\
\hline $20-30$ & 3 & 2 & 9.4 \\
\hline $31-40$ & 4 & 4 & 15.1 \\
\hline $41-50$ & 7 & 6 & 24.5 \\
\hline $51-60$ & 8 & 6 & 26.4 \\
\hline $61-70$ & 6 & 4 & 18.9 \\
\hline $71-80$ & 2 & 1 & 5.7 \\
\hline Total & $\mathbf{3 0}$ & $\mathbf{2 3}$ & $\mathbf{1 0 0}$ \\
\hline
\end{tabular}

Table 2: Findings of general examination. Hypertension was defined as blood pressure more than 140/90 MM Hg

\begin{tabular}{|c|c|c|c|}
\hline \multicolumn{2}{|l|}{ Findings } & No. & $\%$ \\
\hline \multicolumn{2}{|l|}{ Pallor } & 47 & 88.7 \\
\hline \multicolumn{2}{|l|}{ Elevated JVP } & 10 & 19.2 \\
\hline \multicolumn{2}{|l|}{ Pedal edema } & 33 & 62.26 \\
\hline \multirow[t]{2}{*}{ Hypertension } & Standing & 25 & 47.2 \\
\hline & Lying & 29 & 35.8 \\
\hline \multicolumn{2}{|l|}{ Gallop rhythm } & 8 & 15.1 \\
\hline \multicolumn{2}{|c|}{ Systolic murmur } & 34 & 64.2 \\
\hline \multicolumn{2}{|l|}{ Pericardial rub } & 11 & 20.8 \\
\hline
\end{tabular}

prolonged QTc, cor pulmonale, $\mathrm{T}$ wave inversion, low voltage complex and conduction disturbance. (Table 3). The echocardiography findings were left ventricular diastolic dysfunction, left ventricular hypertrophy (overall), pericardial effusion and valvular lesions i.e. mitral and tricuspid regurgitation. We lost seven patients during the study, three due to hyperkalemia, other three due to refractory pulmonary edema and one due to acute myocardial infarction. 
Table 3: ECG findings

\begin{tabular}{|l|c|c|}
\hline ECG findings & No. & $\%$ \\
\hline Normal & 10 & 18.9 \\
\hline T inversion & 5 & 9.4 \\
\hline Prolonged QTc & 6 & 10.4 \\
\hline Low voltage complex & 4 & 7.6 \\
\hline Conduction disturbance & 4 & 7.6 \\
\hline LAD & 3 & 5.7 \\
\hline Cor Pulmonale & 5 & 9.5 \\
\hline Sinus tachycardia & 1 & 1.9 \\
\hline PVCs & 1 & 1.9 \\
\hline Tall t waves & 3 & 5.7 \\
\hline
\end{tabular}

\section{DISCUSSION}

On general physical examination, pedal edema was observed in $62.26 \%$, hypertension in 47.2 $\%$ on standing position and $35.8 \%$ in lying position and systolic murmur was heard in $64.25 \%$. Congestive heart failure (CHF) suggested by the presence of gallop rhythm (S3/S4) was seen in $15.1 \%$. CHF was observed in $31 \%$ of patients at the start of dialysis in the study conducted by Kent $G$ et $\mathrm{al}^{8}$. Cheung et al. in his study reported that $80 \%$ of patients with chronic kidney disease suffered from various cardiac diseases, out of which CHF constituted forty percent ${ }^{9}$. Findings of our study are also similar to that of Barre $\mathrm{P}$ E et al. who found $31 \%$ of cases with cardiac failure at the start of dialysis ${ }^{10}$.

Various studies have reported pericardial effusion in addition to ventricular dysfunction in such patients ${ }^{11,12}$. In the present study, echocardiography showed pericardial effusion in 17 patients $(32.1 \%)$. One patient had moderate effusion and the remaining sixteen had mild effusion. In a study done by Frommer et $\mathrm{al}^{13}$. pre-dialysis effusions was present in thirty six percent of patients.

It was seen that left ventricular diastolic dysfunction was more common as compared to left ventricular systolic dysfunction. 58.5\% patients had left ventricular diastolic dysfunction whereas only $13.2 \%$ patients had left ventricular systolic dysfunction. Zocalli et al. had found left ventricular systolic dysfunction in $15 \%$ while left ventricular diastolic dysfunction was in $32 \%$ of their subjects $^{14}$.

Table 4: Echocardiography findings

\begin{tabular}{|l|c|c|}
\hline Echo findings & No. & $\%$ \\
\hline Left ventricular hypertrophy & & \\
\hline Overall & 26 & 49.1 \\
\hline Concentric & 18 & 33.9 \\
\hline Eccentric & 0 & 0 \\
\hline LV Diastolic dysfunction & 31 & 58.5 \\
\hline LV Systolic dysfunction & 7 & 13.2 \\
\hline Pericardial effusion & 17 & 32.1 \\
\hline Left atrial dilatation & 4 & 7.5 \\
\hline Left ventricular dilatation & 4 & 7.5 \\
\hline All chamber dilatation & 2 & 3.8 \\
\hline Global hypokinesia & 1 & 5.2 \\
\hline Basal septal hypertrophy & 1 & 1.9 \\
\hline Valvular lesions & & \\
\hline Mitral Regurgitation & 89 & 83.1 \\
\hline Aortic Regurgitation & 21 & 39.6 \\
\hline Tricuspid Regurgitation & 31 & 58.5 \\
\hline Pulmonary Regurgitation & 2 & 3.8 \\
\hline
\end{tabular}


Left ventricular hypertrophy (LVH) was diagnosed by ECG in 3 patients (5.7 \%). Echocardiography showed LVH of overall type in 26 patients $(49.1 \%)$. Left ventricular hypertrophy was observed in $65 \%$ of subjects by Straumann et al ${ }^{15}$. Parfrey PS et al. have also found that the characteristic echocardiography pattern in dialysis patients were a dilated left ventricle with normal systolic function and left ventricular hypertrophy. ${ }^{16}$

Regarding mortality during maintenance hemodialysis, Jungers et al. have shown that cardiovascular disease is the major cause of morbidity and mortality in CKD patients both pre-dialysis and on maintenance dialysis therapy. Cardiovascular mortality is 3 to 20 times higher in ESRD patients than general population of similar age ${ }^{17}$. Similarly, Koch et al. noted that cardiac death was responsible for most fatalities in diabetic mellitus patients with ESRD $^{20 .}$

Seven cases reported chest pain and five had ischemic changes in ECG showing $\mathrm{T}$ wave inversion in our study. Lisowsky et al. have reported that forty of their cases suffered from coronary artery disease ${ }^{18}$. Chueng et al. have shown that cardiac cause is responsible for $39.4 \%$ of all the deaths and of which ischemic heart disease constituted $61.5 \% 19$.

\section{CONCLUSION}

In patients undergoing maintenance hemodialysis for ESRD, common clinical findings were pallor, systolic murmur, pedal edema and hypertension. ECG findings were prolonged QTc, Cor Pulmonale, $\mathrm{T}$ wave inversion, low voltage complex and conduction disturbance and echo findings were left ventricular diastolic dysfunction, left ventricular hypertrophy (overall), pericardial effusion and valvular lesions i.e. mitral and tricuspid regurgitation. Total mortality during the period of study was $11.1 \%$. These findings of Nepalese population were not different from the findings of other populations of the west.

\section{REFERENCES}

1. Xu G, Huang T. Hepatitis B virus associated glomerular nephritis in East Asia; progress and challenge. Eur J Intern Med.2011 Apr; 22 (2):161-6 http://dx.doi.org/10.1016/ j.ejim.2010.11.005

2. Fabrizi F, Martin P, Cacoub P, Messa P, Donato FM. Treatment of hepatitis C related kidney disease. Expert Opin Pharmacother. 2015 Aug;16(12);1815-27 http://dx.doi.org/ $\underline{10.1517 / 14656566.2015 .1066333}$

3. Adedeji TA, Adedeji NO, Adebisi SA, Idow AA, Fawala MB, Jimoh KA. J Int Assoc Provid AID care.2015,26:434-40

4. U.S. Renal Data System, USRDA 1991 Annual Report, Bethesda. The National Institute of Diabetes and Digestive and Kidney Diseases. 1991

5.Greaves SC, Sharpe DN: Cardiovascular disease in patients with end-stage renal failure. Aust NZ J Med.1992; 22:153-8 ht tp://dx.doi.org/10.1111/j. 1445-5994.1992.tb02797.x

6. Koren MJ, Devereux RB, Casale PN, Savage DD, Laragh JH: Relation of left ventricular mass and geometry to morbidity and mortality in uncomplicated essential hypertension. Ann intern Med. 1991;114:345-352 http://dx.doi.org/ $\underline{10.7326 / 0003-4819-114-5-345}$

7. Lindner A, Charra B, Sherrard DJ, Scribner BH: Accelerated atherosclerosis in 
prolonged maintenance hemodialysis. N Eng1 J Med.1974; 290: 697-701

8. Kent GM, Foley RN, Parfrey PS, Harnett JD, Martin CJ, Murray DC, Barre PE. Clinical and electrocardiographic disease in patients starting ESRD therapy. Kidney Int. 1995 Jan; 47(1):186-92 http://dx.doi.org/ $\underline{10.1038 / \mathrm{ki} .1995 .22}$

9. Cheung AK, Sarnak MJ, Yan G, Berkoben $\mathrm{M}$, Heyka $\mathrm{R}$ et al. Cardiac diseases in maintenance hemodialysis patients: Results of the HEMO study. Kidney Int.2004 Jun;65 (6):2380-9 http://dx.doi.org/10.1111/j. 1523-1755.2004.00657.x

10. Barre PE, Foley RN, Parfrey PS, Harnett JD, Foley RN, Kent GM, Murray D et al. Congestive heart failure in dialysis patients: prevalence, incidence, prognosis and risk factors. Kidney International.1995 Mar; 47(3):884-90 http://dx.doi.org/10.1038/ki. 1995.132

11. Peraino RA. Pericardial effusion in patients treated with maintenance dialysis. Am J Nephrol.1983 Nov-Dec; 3(6): 319-22 http:// dx.doi.org/10.1159/000166740

12. Robert N Foley, Patrick S Parfrey, John D Harnett, Gloria M Kent, Christopher J Martin et al. Clinical and echocardiographic disease in patients starting end-stage renal disease therapy. Kidney International. 1995; 47:186-192. http://dx.doi.org/10.1038/ki. $\underline{1995.22}$

13. Frommer JP, Young JB, Ayus JC. Asymptomatic pericardial effusion in uremic patients: effect of long-term dialysis. Nephron.1985;39(4):296-301 http:// dx.doi.org/10.1159/000183393
14. Zocalli C, Benedetto FA, Mallamaci F, Tripepi G, Giacone G et al. Prognostic value of echocardiographic indicators of left ventricular systolic function in asymptomatic dialysis patients. J Am Soc Nephrol.2004 Apr;15(4):1029-37 http:// dx.doi.org/10.1097/01.A S N. $\underline{0000117977.14912 .91}$

15. Straumann E, Bertel O, Meyer B, Weiss P, Misteli $\mathrm{M}$ et al. Symmetric and asymmetric left ventricular hypertrophy in patients with end stage renal failure on long term hemodialysis. Clin Cardioal.1998 Sep; 21(9):672-8 http://dx.doi.org/10.1002/clc. $\underline{4960210913}$

16. Parfey PS. Cardiac and cerebrovascular disease in chornic uremia. Am J Kidney Dis. 1993 Jan;21(1):77-80 http://dx.doi.org/ 10.1016/S0272-6386(12)80726-8

17. Jungers $P$, Qualim Z, Nguyen-Khao T, Massy Z, London G. Cardioprotection: An essential component for predialysis chronic renal failure treatment. Nephrologie. 2003;24(2):79-80

18. Liwosky A, Musial WJ. Heart failure in patients with chronic kidney disease. Rocz Akad Med Bialymst.2004;49:162-5.

19. Parfrey PS, Foley RN. Ischemic heart disease in chronic uremia. Blood purification.1996;14(40):321-6 http:// dx.doi.org/10.1159/000170280

20. Koch M, Thomas B, Tschope W, Ritz E. Survival and predictors of death in dialysed diabetic patients. Diabetologia.1993 Oct; 10:1113-7 http://dx.doi.org/10.1007/ BF02374508 